\title{
One Health approach to tackle antimicrobial resistance in South East Asia
}

\author{
Multisectoral action is essential to control the problem
}

1

ntimicrobial resistance (AMR) has become a core political, social, and economic problem of our time. The efficacy of antimicrobials is declining rapidly, alongside the emergence of pan-resistant bacteria and uncontrolled dissemination of antibiotic resistant genes in non-clinical environments. Projections suggest that by 2050 more people will die of bacterial infections than cancer. ${ }^{1}$

The 71st session of the UN General Assembly identified AMR as a dominant global health concern, placing it high on the agenda of national policy makers, international organisations, and financial institutions in developed and developing countries alike. ${ }^{23}$

This special collection of The BMJ highlights the critical situation of AMR in South East Asia. The WHO South East Asia region (SEAR: Bangladesh, Bhutan, Democratic Peoples' Republic of Korea, India, Indonesia, Maldives, Myanmar, Nepal, Sri Lanka Thailand, Timor Leste) comprises low and middle income countries and is home to around 1.8 billion people. A qualitative risk assessment in this collection shows that the region is possibly at the highest risk globally for emergence and spread of AMR. ${ }^{4}$

Although the region has made steady social and economic progress, a large proportion of the population continues to live in poverty. Inadequate housing and sanitation accelerate person-to-person and environmental spread of resistant pathogens and genes.

Antibiotic stewardship programmes also remain underdeveloped. High use of antibiotics in hospitals and transmission of resistant pathogens between patients and to health workers accelerates spread of resistance. System-wide monitoring of measures such as infection prevention and control and awareness of healthcare workers is lacking.

Regulation of production and sale of antibiotics is weak. Antibiotics are readily available over the counter without prescription in many countries in the region, resulting in indiscriminate use. The dissemination of counterfeit or substandard antibiotics by unscrupulous producers in the absence of credible drug regulations and law enforcement also contributes to increased resistance. Research and development of newer antimicrobials is inadequate. There is a need to establish new treatments while preserving the efficacy of existing ones.

Furthermore, widespread diffusion of resistant bacteria and genes occurs in the environment and food systems. Coliform contamination of piped water in Asia is among the highest in the world, with antibiotic resistant genes recorded in drinking water supply systems in several of the region's countries. Indiscriminate use of antibiotics in livestock and aquaculture for treatment and growth promotion has hastened emergence and spread of foodborne antibiotic resistant pathogens.

Overall, weak governance and poor enforcement of policies and legislations have led to slow action on AMR in the region. The problem has risen to prominence in the health policy agenda over the past few years. In 2011, health ministers in the South East Asia region adopted the Jaipur Declaration on Antimicrobial Resistance, which calls for comprehensive action against the irrational use of antibiotics. ${ }^{5}$ At the 2015 regional committee meeting in Timor Leste, member states passed a key resolution for steadfast political commitment and multisectoral coordination to tackle AMR. ${ }^{6}$ Most recently, the Berlin declaration of the G20 health ministers in May 2017 recognised the increasing threat of AMR and outlined various measures to address it. ${ }^{7}$ The region's member states have pledged to develop national action plans to tackle AMR, in line with the One Health approach, with interventions aimed at agriculture, livestock, and human health. ${ }^{8}$

As these initiatives show, AMR is now considered a clear and present danger to health, development, and prosperity across the region. But is increased awareness among policymakers translating into real change?

In this collection of articles, we provide an in-depth look into recent initiatives against AMR in three of the region's countries-India, Indonesia, and Thailand. We also survey the broader situation regarding progress on national action plans, surveillance, infection prevention and control, and spread of antibiotic resistant genes in the environment. The collection also highlights priorities for action, including successful implementation of the One Health approach and a stronger surveillance system.

Much depends on adequate investment in national action plans. The WHO South East Asia Regional Office is committed to ensure that national action plans are fully implemented across the region and compliance with the global action plan is achieved. The national action plans will provide a necessary framework for action and must be supported by good governance, multisectoral collaboration, and ongoing monitoring.

With the national action plans as national references the coming years will prove pivotal to sustain momentum in translating awareness into actions and pushing AMR to the top of the regional agenda.

Competing interests: I have read and understood BM policy on declaration of interests and have no relevant interests to declare.

Provenance and peer review: Commissioned; not externally peer reviewed.

This article is one of a series commissioned by The $B M$ based on an idea from WHO SEARO. The BM/ retained full editorial control over external peer review, editing, and publication. Open access fees are funded by the WHO SEARO.

This is an Open Access article distributed unde the terms of the Creative Commons Attribution IGO License (https://creativecommons.org/licenses/bync/3.0/igo/), which permits use, distribution, and reproduction for non-commercial purposes in any medium, provided the original work is properly cited.

Poonam Singh,

World Health Organization, South East Asia Region, New Delhi, India

singhpoonam@who.int

Cite this as: BMJ 2017;358:j3625 http://dx.doi.org/10.1136/bmj.j3625 